\title{
DOUBLE RIGHT TESTICULAR ARTERIES WITH ITS EMBRYOLOGICAL BASIS: A CASE REPORT
}

Anita Shriram Fating 1

\section{HOW TO CITE THIS ARTICLE:}

Anita Shriram Fating. "Double Right Testicular Arteries with its Embryological Basis: A Case Report". Journal of Evolution of Medical and Dental Sciences 2015; Vol. 4, Issue 53, July 02; Page: 9272-9275,

DOI: $10.14260 /$ jemds/2015/1346

ABSTRACT: Variations in the origin of arteries in the abdomen are very common but with the advent of new operative and laparoscopic techniques within the abdominal cavity, the anatomy of the abdominal vessels has assumed much more clinical importance. During routine dissection for MBBS of the abdominal cavity, we came across double right testicular arteries in a middle aged male cadaver. Testicular arterial morphology deviating from its normal anatomy is a serious concern, as diagnostic approaches in male infertility and varicocele can be often linked with its associated vascular anomaly. The origin and course of the testicular artery must be carefully identified in order to preserve normal blood circulation and prevent testicular atrophy. Radiologists, urologists and oncologists should be familiar with testicular artery variants in order to provide an accurate diagnosis during pre-operative studies. Knowledge of this variation will help to avoid clinical complications especially during radiological examination and/or surgical approaches in abdominal region.

KEYWORDS: Abdominal vessels, Testicular arteries, Variation.

INTRODUCTION: Reproduction is a fundamental process that allows the living organisms to preserve their progeny and evolve by transmitting genes. The testis is an important reproductive organ, upon which the survival of the human species depends. The testicular vessels play major role in the thermoregulation of this organ.[1]

The testicular arteries are paired vessels that usually arise from abdominal aorta at the second vertebral level. Each artery passes obliquely downwards and posterior to the peritoneum. Descending on the posterior abdominal wall, each reaches the deep inguinal ring where it enters the spermatic cord. Along their course, the testicular arteries are accompanied by the testicular veins. The testicular artery supplies the perirenal fat, ureter and external iliac lymph nodes; while in the inguinal canal, it supplies the cremaster muscle.[2]

The awareness of variations of testicular arteries about its origin, course, number \& even branches is of particular interest in developmental biology and surgical anatomy. Moreover, such variations could result in compression of the vessels causing testicular and pelvic varicocele, hypertension, proteinuria and albuminuria.[3]

CASE REPORT: During routine dissection of the abdominal cavity for MBBS, we came across double unilateral testicular arteries on the right side of a middle aged cadaver $\{$ Fig. 1$\}$. Both right testicular arteries were originated from abdominal aorta, labelled as superior testicular and inferior testicular arteries. The right superior testicular artery took origin at the normal level and crossed right ureter, right psoas major muscle and inferior vena cava while the right inferior testicular artery took origin 3 $\mathrm{cm}$ below the superior testicular artery above bifurcation of abdominal aorta and crossed right common iliac artery. Both the arteries entered into right spermatic cord to supply right testis. 
DISCUSSION: Anatomical variations of testicular arteries with regard to their origin have been reported in $4.7 \%(\mathrm{~N}=150)$ of cases. They were found to take origin either from unusually high level of aorta or from the renal artery. ${ }^{[4]}$ Unusual origin or course of the testicular artery may be of surgical importance in carrying out specific surgical procedures involving it or in diagnostic pathology related to testicular anatomy.[5] Variations in the origin of the normal single testicular artery have been commonly reported by various authors. The testicular arteries may vary at the origin, they may be missing, or may originate from the renal artery, middle supra renal artery, one of the lumbar arteries, common or internal iliac artery, or from the superior epigastric artery.[2,5] They may arise from a common trunk, and may be two, three or four on one side.[5]

Machnicki and Grzybiak examined the variation of testicular artery in fetuses and adults. According to their site of origin from the aorta or renal arteries four main types of testicular arteries have been identified:

Type 1: A single testicular artery arising from the aorta.

Type 2: A single testicular artery arising from the renal artery.

Type 3: Two testicular arteries arising from the aorta and penetrating the same gonad.

Type 4: Two testicular arteries penetrating the testes. One arising from the aorta and other from the renal artery.[6]

Variation in the present case was of type 3: In a study of 40 cadavers by G. V. Mohandas, right testicular artery arose from right renal artery in one and from aorta close to the origin of inferior mesentric artery in another one.[7]

Pai and Vadgaokar in their study found variations of testicular arteries in $14.7 \%$ (34 adult male cadavers aged 40-60 years) of cases. The following variations were seen in their study:

Variation 1: The testicular artery was a branch of aberrant renal artery for lower pole of kidney. This anomalous pattern was seen in five cadavers (7.4\%), out of which three were on the right side and two on the left.

Variation 2: The testicular artery was a branch of the renal artery. This anomalous pattern was seen on the right side of only one cadaver $(1.4 \%)$.

Variation 3: High origin of testicular artery. This anomalous pattern was seen on the left sides of three cadavers (4.4\%).

Variation 4: Double testicular artery. This anomalous pattern was seen on the right side of only one cadaver (1.4\%).[8]

The variation in the present study belongs to variation 4: In a study of Notkovich including 405 testicular or ovarian arteries the gonadal arteries of renal origin were found in $14 \%$ taking their origin from principal renal artery, from its branches or from an accessory renal artery.[9] An additional left testicular artery originated from the ventrolateral wall of the descending aorta has been reported by Loukas and Stewart.[10] High origin of the gonadal arteries from the abdominal aorta have been reported in two individuals by Ozan $\mathrm{H}$ et al.[11] Double testicular arteries were seen on the left side, with the superior testicular artery arising from the inferior renal artery and the inferior testicular artery arising directly from the abdominal aorta.[12] Jyothsna P. reported double left testicular arteries.[13] Although several kinds of variations of the origin, direction and course of the testicular arteries have been described, this is a rare case of double testicular arteries on the right side, both taking origin from abdominal aorta. 
Variations of the testicular arteries are based upon their embryonic origin. The first note on the embryological origin of the gonadal artery was made by Felix in 1912[14] and he mentioned that nine lateral mesonephric arteries are divided into the cranial, middle and caudal group, one of the caudal arteries usually persists and differentiates into the definitive gonadal artery. ${ }^{[8]}$ The persistence of a cranial lateral mesonephric artery results in a high-origin of the gonadal artery, ${ }^{[15]}$ probably from the suprarenal or from a more superior aortic level. Persistence of more than one lateral mesonephric arteries result in double, triple or quadruple gonadal arteries. ${ }^{[8,15]}$ Double right testicular artery as reported in the present case is one of the rare variation, which may be due to persistent lateral splanchnic arteries.

Recently the anatomy of the gonadal arteries has assumed importance because of the development of a new operative techniques within the abdominal cavity for operations such as varicocele and undescended testes. During laparoscopic surgery of the male abdomen and pelvis many complications occurred due to unfamiliar anatomy in the operative field. Awareness of variations of the testicular arteries shown in this case report, becomes important during such surgical procedures such as varicocelectomy and microvascular autotransplantation of intraabdominal testis. So many complications could be avoided with the accurate knowledge of testicular arterial variations. Thus it becomes imperative to carefully preserve the gonadal artery in order to prevent any vascular troubles of gonad, the gonadal artery being its unique source of blood supply. Thus, the study of such kind of variations of testicular artery is of immence help to Surgeons, Radiologists, Urologists and Oncologists.

Fig. 1: Showing Right Double Testicular Arteries.

a-Right superior testicular artery, b- Right inferior testicular artery, c- Abdominal aorta, dBifurcation of abdominal aorta, e- Inferior vena cava, f- Right psoas major muscle , g- Right ureter and h-Right common iliac artery

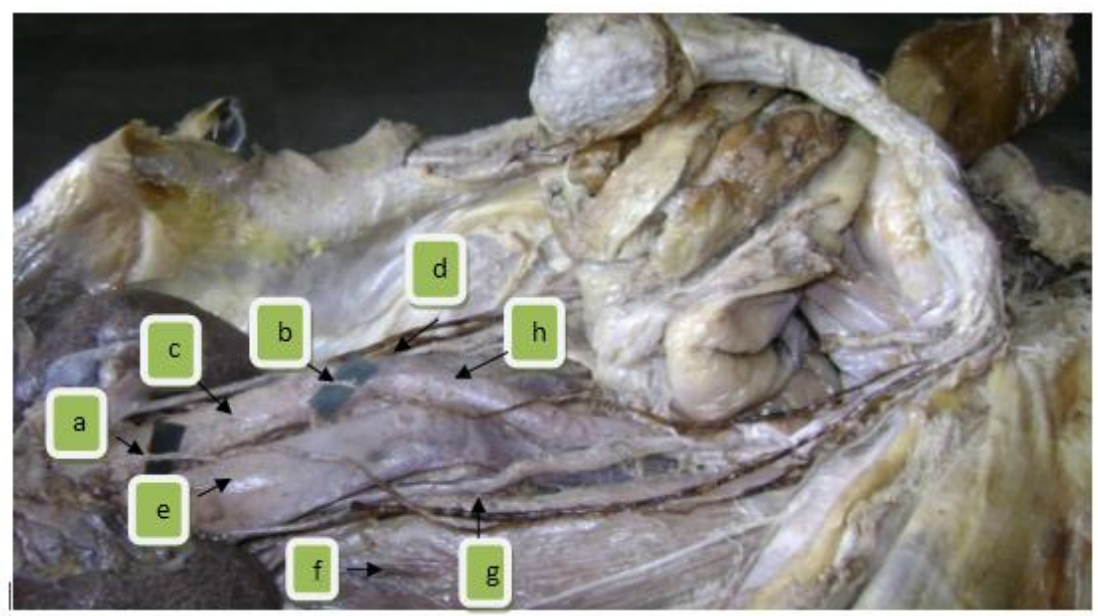

Fig. 1:

\section{REFERENCES:}

1. Ranade AV, Rai R, Prabhu LV, Mangala K, Nayak SR. Arched left gonadal artery over the left renal vein associated with double left renal artery. Singapore Med J. 2007; 48(12): e332-e334.

2. Hollinshead WH. Anatomy for surgeons. Vol. 2. New York, Harper and Row. 1971; 579-580. 
3. Adebisi SS, Singh SP. Anomalous gonadal arteries in relation to the renal vein: A preliminary study in Nigerians. Nigerian J Surg Res. 2000; 2: 148-151.

4. Samuel Asala, Shyama C. Chaudhary M. Bidmos. Anatomical variations in the human testicular blood vessels. Annals of anatomy - Anatomischer Anzeiga. 2001 Nov; 183(6): 545-549.

5. Bergman RA, Cassell MD, Sahinoglu K, Heidger PM Jr. Human doubled renal and testicular arteries. Anat Anz, 1992; 174: 313-315.

6. Machnicki A, Grzybiak M. Variations in testicular arteries in fetuses and adults. Folia Morphol (Warsz) 1997; 56: 277-85.

7. G. V. Mohandas, B. M. Ismail, K. Vijayalakshmi, V. Sunitha, B. Devi, Ch. Rojarani, V. Durgesh. Source of origin of Testicular artery: A cadaveric study. Journal of Evidence Based Medicine and Healthcare.2014; 1(2): 1-4.

8. Pai MM, Vadagaonkar R, Rai R, Nayak SR, Jiji RJ, Ranade A, Prabhu LV, Madhyarstha S. A cadaveric study of the testicular artery in the south Indian population. Singapore Med J 2008; 49(7): 551-554.

9. Notkovich.H.Variation of the testicular and ovarian arteries in relation to the renal pedicle. Surg Gynecol Obstet 1956; 103: 487-495.

10. Loukas M, Stewart D. A case of an accessory testicular artery, Folia Morphol(Warsz), 2004, 63(3):355-357.

11. Ozan H, Gumusalan Y, Onderoglu S, Simsek C. High origin of gonadal arteries associated with other variations. Anat Anaz. 1995; 177: 156-160.

12. Soni S., Wadhwa A. Multiple variations in the paired arteries of abdominal aorta-Clinical Implications, Journal of Clinical and Diagnostic Research. 2010; 4(3): 2622-2625.

13. Jyothsna P, Mohandas Rao KG, Somayaji SN, Ashwini LS. Multiple Vascular Anomalies Involving Testicular, Suprarenal Arteries and Lumbar Veins. North American Journal of Medical Sciences. 2012; 4(3) 154-156.

14. Felix W. Mesonephric arteries (aa. Mesonephricae). In: Keibel F, Mall FP, Manual of Human Embryology. 1912; Vol 2. Philadelphia: Lippincott: 820.

15. Cicekcibasi AE, Salbacak A. The origin of gonadal arteries in human fetuses: anatomical variations Ann Anat. 2002; 184: 275-279.

\section{AUTHORS:}

1. Anita Shriram Fating

\section{PARTICULARS OF CONTRIBUTORS:}

1. Associate Professor, Department of Anatomy, Padmashree Dr, Vithalrao Vikhe Patil Foundation's Medical College, Viladghat, Ahmednagar, Maharashtra.
NAME ADDRESS EMAIL ID OF THE CORRESPONDING AUTHOR:

Dr. Anita Shriram Fating, Associate Professor, Department of Anatomy, Padmashree Dr, Vithalrao Vikhe Patil Foundation's Medical College, Viladghat, Ahmednagar-414111, Maharashtra. E-mail: aanujdeshmukh@rediffmail.com

Date of Submission: 09/06/2015.

Date of Peer Review: 10/06/2015.

Date of Acceptance: 24/06/2015.

Date of Publishing: 02/07/2015. 